\title{
EFICIÊNCIA NUTRICIONAL DE MUDAS DE Stryphnodendron polyphyllum EM FUNÇÃO DE NITROGÊNIO E FÓSFORO
}

\section{NUTRITIONAL EFFICIENCY OF Stryphnodendron polyphyllum SEEDLINGS IN FUNCTION OF NITROGEN AND PHOSPHORUS}

\author{
Natália Hilgert de Souza Carnevali ${ }^{1}$ Marlene Estevão Marchetti ${ }^{2}$ Maria do Carmo Vieira ${ }^{2}$ \\ Thiago de Oliveira Carnevali ${ }^{3}$ Diovany Doffinger Ramos ${ }^{4}$
}

\begin{abstract}
RESUMO
Devido à carência de estudos agronômicos com espécies nativas e da importância do adequado fornecimento de nutrientes às plantas, objetivou-se neste trabalho avaliar o efeito de doses de $\mathrm{N}$ e $\mathrm{P}$ sobre o teor e conteúdo de nutrientes, bem como na eficiência nutricional de mudas de barbatimão (Stryphnodendron polyphyllum), em Latossolo Vermelho distroférrico. O trabalho foi desenvolvido em vasos de $8 \mathrm{dm}^{3}$ mantidos em casa de vegetação. Foram estudadas quatro doses de $\mathrm{N}\left(0 ; 20,82 ; 41,64\right.$ e $62,46 \mathrm{mg} \mathrm{kg}^{-1}$ de $\left.\mathrm{N}\right)$ e quatro doses de $\mathrm{P}$ $\left(0 ; 41,72 ; 83,44\right.$ e $\left.125,16 \mathrm{mg} \mathrm{kg}^{-1} \mathrm{de}_{\mathrm{P}_{2}} \mathrm{O}_{5}\right)$, em esquema fatorial $4 \mathrm{x} 4$, no delineamento experimental de blocos casualizados, com quatro repetições. Decorridos 210 dias após a semeadura avaliou-se massa seca da parte aérea e radicular e teor de macro e micronutrientes na planta; por meio desses dados foram calculados os índices de eficiência de absorção e utilização de nutrientes. Houve interação significativa entre as doses de $\mathrm{N}$ e $\mathrm{P}$ para os teores de $\mathrm{P}, \mathrm{K}, \mathrm{Ca}, \mathrm{Cu}, \mathrm{Mn}$ e $\mathrm{Zn}$ na parte aérea e $\mathrm{N}, \mathrm{P}, \mathrm{K}, \mathrm{Ca}, \mathrm{Mg}$ e Fe na raiz. Na parte aérea das mudas, os nutrientes $\mathrm{N}$ e Fe foram influenciados somente pelo efeito isolado das doses de $\mathrm{N}$, e o teor de $\mathrm{Mg}$ pelo efeito isolado das doses de $\mathrm{P}$. O conteúdo de todos os nutrientes, na parte aérea e na raiz, foi influenciado significativamente pela interação entre as doses de $\mathrm{N}$ e P. As máximas doses proporcionaram maior conteúdo de macronutrientes na parte aérea, exceto $\mathrm{N}$ e $\mathrm{K}$. O conteúdo de micronutrientes na parte aérea aumentou em função das doses de $\mathrm{N}$ e $\mathrm{P}$ e reduziu na raiz, exceto $\mathrm{Fe}$. As mudas de barbatimão mostraram-se mais eficientes em absorver $\mathrm{N}$ e $\mathrm{Zn}$ e utilizar $\mathrm{P}$ e $\mathrm{Mg}$. Comparados ao conteúdo, o $\mathrm{N}$ e o $\mathrm{Ca}$ foram os nutrientes mais acumulados nos tecidos da planta, contudo, os que apresentaram menor valor (P e Mg) foram os nutrientes mais eficientemente utilizados.
\end{abstract}

Palavras-chave: barbatimão; nutrição; absorção; translocação.

\section{ABSTRACT}

Due to lack of agronomic studies with native species and the importance of an adequate supply of nutrients to plants, this study aimed to evaluate the effect of $\mathrm{N}$ and $\mathrm{P}$ on the concentration and nutrient content as well as the nutritional efficiency of barbatimão (Stryphnodendron polyphyllum) seedlings in Oxisol. The study was conducted in $8 \mathrm{dm}^{3}$ pots and kept in a greenhouse. Were studied four doses of $\mathrm{N}(0,20.82,41.64$ and $\left.62.46 \mathrm{mg} \mathrm{kg}^{-1} \mathrm{~N}\right)$ and four doses of $\mathrm{P}\left(0,41.72,83.44\right.$ and $\left.125.16 \mathrm{mg} \mathrm{kg}^{-1} \mathrm{P}_{2} \mathrm{O}_{5}\right)$ in $4 \times 4$ factorial in randomized complete block design with four replications. After 210 days after sowing was evaluated dry mass of shoots and roots and nutrient concentration in the plant, through these data were calculated the

1 Bióloga, Dra., Universidade Estadual de Mato Grosso do Sul, BR163, Km 20,2 saída para Dourados, CEP 79980-000, Mundo Novo (MS), Brasil. natalia_hilgert@hotmail.com

2 Engenheira Agrônoma, Dra., Professora Adjunta da Faculdade de Ciências Agrárias, Universidade Federal da Grande Dourados, Rod. Dourados-Itahum, Km 12, Cidade Universitária, CEP 79804-970, Dourados (MS), Brasil. marlenemarchetti@ufgd.edu.br/vieiracm@terra.com.br

3 Biólogo, Dr., Faculdade de Ciências Agrárias, Universidade Federal da Grande Dourados, Rod. Dourados-Itahum, Km 12, Cidade Universitária, CEP 79804-970, Dourados (MS), Brasil. thiagocarnevali@live.com

4 Biólogo, Dr., Professor Adjunto do Centro de Ciências Humanas e Sociais da Universidade Federal do Mato Grosso do Sul, Cidade Universitária, Caixa Postal 549, CEP 79070-900, Campo Grande (MS), Brasil. diovany3@hotmail.com

Recebido para publicação em 31/07/2012 e aceito em 11/09/2014 
efficiency of absorption and utilization of nutrients. There was significant interaction between doses of $\mathrm{N}$ and $\mathrm{P}$ to the concentration of $\mathrm{P}, \mathrm{K}, \mathrm{Ca}, \mathrm{Cu}, \mathrm{Mn}$ and $\mathrm{Zn}$ in shoots and $\mathrm{N}, \mathrm{P}, \mathrm{K}, \mathrm{Ca}, \mathrm{Mg}$ and $\mathrm{Fe}$ in the root. In seedling nutrients $\mathrm{N}$ and $\mathrm{Fe}$ were influenced only by the isolated effect of $\mathrm{N}$ levels, and $\mathrm{Mg}$ content by isolated effect of P levels. The content of all nutrients in the shoot and root was significantly influenced by the interaction between doses of $\mathrm{N}$ and $\mathrm{P}$. The maximum doses provided greater nutrient contents in shoots, except for $\mathrm{N}$ and $\mathrm{K}$. The micronutrients content in the shoot increased as a function of both $\mathrm{N}$ and $\mathrm{P}$ and reduced the root, except Fe. The barbatimão seedlings were more efficient at absorbing $\mathrm{N}$ and $\mathrm{Zn}$ and using $\mathrm{P}$ and $\mathrm{Mg}$. Comparing the content, $\mathrm{N}$ and $\mathrm{Ca}$ were the nutrients that most accumulated on the plant tissues, however, those who had lower (P and $\mathrm{Mg}$ ) were the nutrients more efficiently used.

Keywords: barbatimão; nutrition; absorption; translocation.

\section{INTRODUÇÃO}

O barbatimão Stryphnodendron polyphyllum (Mart.) é uma leguminosa arbórea, nativa do Cerrado, que apresenta várias utilidades para o homem. Dentre as propriedades medicinais destacam-se ações anti-inflamatória, antibacteriana, antidiarreica (RODRIGUES; CARVALHO, 2001), cicatrizante de lesões gástricas e contra leishmaniose (LORENZI, 2002). A casca é a principal parte da planta utilizada na medicina popular devido à sua alta concentração de taninos (LOPES et al., 2009). Borges Filho e Felfili (2003) destacam que o extrativismo da casca ocorre até mesmo em unidades de conservação, colocando a espécie em risco de extinção. O barbatimão é recomendado para recuperação de áreas degradadas por ser uma espécie adaptada às condições edáficas álicas dos solos de Cerrado e por ser uma leguminosa micorrízica (SCABORA et al., 2011).

Mesmo diante da consideração de que as plantas nativas do Cerrado são adaptadas aos solos de baixa fertilidade (HARIDASSAN, 2008), estudos experimentais de fertilização indicam que espécies lenhosas respondem à adubação do solo, principalmente ao $\mathrm{N}$ e P (SCHOLZ et al., 2006). Vieira et al. (2011), estudando doses crescentes de N e P sobre o crescimento da guavira (Campomanesia adamantium Cambess.), recomendam o uso de $380 \mathrm{~kg} \mathrm{ha}^{-1}$ de $\mathrm{P}$ e de $114 \mathrm{~kg} \mathrm{ha}^{-1}$ de $\mathrm{N}$ para melhor desenvolvimento inicial da espécie. Calgaro et al. (2008), ao estudarem os efeitos da adubação química e orgânica na fertilidade de um subsolo degradado e na micorrização do Stryphnodendron polyphyllum, verificaram maior crescimento das plantas, principalmente as que receberam calagem associada a $\mathrm{N}+\mathrm{P}$ e resíduos orgânicos.

São escassos os trabalhos referentes à utilização de índices para avaliação da eficiência nutricional de plantas nativas, todavia, esses estudos forneceriam informações importantes sobre a habilidade de uma espécie crescer e se desenvolver em solos ácidos e deficientes em nutrientes. Estudos apontam, até agora, que muitas espécies nativas respondem à adubação, sendo o $\mathrm{N}$ e o $\mathrm{P}$ os elementos mais limitantes para o crescimento (SOUZA et al., 2006; NICOLOSO et al., 2007; SOUZA et al., 2010). Fonseca et al. (2010) verificaram que o padrão de crescimento de Dimorphandra wilsonii sob baixa disponibilidade de nutrientes reflete sua habilidade em crescer em ambientes de menor fertilidade do Cerrado apresentando respostas adaptativas visando à melhoria de sua condição nutricional.

A eficiência nutricional, definida por Goddard e Hollis (1984), é a capacidade que uma planta tem de absorver e utilizar os nutrientes disponíveis. Consequentemente, quando em situação de baixa disponibilidade de nutrientes, as plantas tendem a reduzir a absorção, mas podem utilizá-los de forma mais eficiente, caracterizando a espécie como tolerante à deficiência nutricional (FAGERIA et al., 1988). Por ser um fator controlado geneticamente (PAULA et al., 2003; TOMAZ et al., 2003), a eficiência nutricional de determinada espécie e/ou genótipo pode fornecer subsídios a programas de melhoramento genético, com os quais é possível selecionar espécies com maior capacidade de absorver e assimilar nutrientes quando em condições limitantes.

Estudos sobre eficiência nutricional em espécies nativas do Cerrado são importantes devido às características edáficas álicas e de fixação de P nos solos deste bioma. São solos altamente intemperizados, com reduzida disponibilidade de nutrientes além de alta saturação por alumínio (EBERHARDT etal., 2008). Além disso, apresentam reação ácida, baixa capacidade de troca catiônica e alta capacidade de adsorção aniônica, sendo a fração argila composta principalmente por caulinita, óxidos de $\mathrm{Fe}$ e Al. Os baixos teores de matéria orgânica 
entre 10 e $30 \mathrm{~g} \mathrm{~kg}^{-1}$, resultam em baixo conteúdo de $\mathrm{N}$ potencialmente mineralizável (RESCK et al., 2008). Com isso, a absorção de nutrientes pelas plantas é prejudicada, especialmente em se tratando de nitrogênio $(\mathrm{N})$ e fósforo $(\mathrm{P})$.

Diante da importância do adequado fornecimento de nutrientes às plantas, principalmente na fase de muda, este estudo objetivou avaliar o efeito de doses combinadas de $\mathrm{N}$ e $\mathrm{P}$ no conteúdo de nutrientes e na eficiência nutricional de mudas de barbatimão, em Latossolo Vermelho distroférrico.

\section{MATERIAL E MÉTODOS}

O experimento foi desenvolvido de fevereiro a setembro de 2009, em casa de vegetação, na Universidade Federal da Grande Dourados (UFGD) em Dourados - MS (22 $11^{\prime} 45^{\prime \prime} \mathrm{S}$ e $54^{\circ}$ $55^{\prime} 18^{\prime}$ 'W, altitude de $446 \mathrm{~m}$ ). O clima é do tipo Cwa, segundo a classificação de Köppen. A precipitação média anual é de $1500 \mathrm{~mm}$ e a temperatura média de $22^{\circ} \mathrm{C}$ (EMBRAPA, 2010).

Utilizou-se um Latossolo Vermelho distroférrico de textura argilosa coletado do horizonte B. Suas características químicas foram realizadas seguindo a metodologia proposta por Claessen (1997), com os seguintes resultados: $\mathrm{pH}$ em água $=4,7 ; \mathrm{pH} \mathrm{em} \mathrm{CaCl}_{2}=4,2 ;$ matéria orgânica $=8,2 \mathrm{~g} \mathrm{~kg}^{-1} ; \mathrm{P}=1,0 \mathrm{mg} \mathrm{dm}^{-3}$ (Mehlich 1 ) $\mathrm{K}=0,5$ $\mathrm{mmol}_{\mathrm{c}} \mathrm{dm}^{-3} ; \mathrm{Ca}=4,0 \mathrm{mmol}_{\mathrm{c}} \mathrm{dm}^{-3} ; \mathrm{Mg}=2,0 \mathrm{mmol}_{\mathrm{c}}$ $\mathrm{dm}^{-3} ; \mathrm{Al}=14,1 \mathrm{mmol} \mathrm{dm}_{\mathrm{c}}^{-3} ; \mathrm{H}+\mathrm{Al}=76,0 \mathrm{mmol}_{\mathrm{c}}^{\mathrm{c}}$ $\mathrm{dm}^{-3} ; \mathrm{SB}=6,5 \mathrm{mmol}_{\mathrm{c}} \mathrm{dm}^{-3} ; \mathrm{T}=82,5 \mathrm{mmol}_{\mathrm{c}} \mathrm{dm}^{-3} \mathrm{e}$ $\mathrm{V} \%=7,9$.

O solo foi peneirado em malha de $6 \mathrm{~mm}$ e transferido para vasos de $8 \mathrm{dm}^{3}$. Para elevar a saturação por bases a $60 \%$, utilizou-se calcário dolomítico com PRNT 100\%, incorporado manualmente 30 dias antes da semeadura. Cada vaso foi revestido internamente com sacos plásticos para evitar a perda de água e de nutrientes pela drenagem. Durante todo o período experimental os vasos foram mantidos úmidos a $70 \%$ da capacidade de campo, por meio de pesagem a cada dois dias.

As sementes de barbatimão foram coletadas em agosto de 2008, em Chapadão do Sul/ MS (18 $79^{\circ}$ 'S e $\left.52^{\circ} 62^{\prime} \mathrm{W}\right)$, e armazenadas em sacos de papel em temperatura ambiente. Em fevereiro de 2009, antes da semeadura, efetuou-se tratamento de quebra de dormência das sementes as quais foram embebidas em ácido sulfúrico P.A. por 20 minutos. Foram semeadas de quatro a cinco sementes por vaso, a uma profundidade de $2 \mathrm{~cm}$ e após 30 dias da emergência realizou-se a repicagem das plântulas, mantendo-se as duas mais vigorosas.

Os tratamentos foram constituídos de quatro doses de $\mathrm{N}(0 ; 20,82 ; 41,64$ e $62,46 \mathrm{mg}$ $\mathrm{kg}^{-1}$ de $\mathrm{N}$, correspondentes a $0,50,100$ e $150 \mathrm{~kg}$ ha $\left.^{-1}\right)$ e quatro doses de $\mathrm{P}(0 ; 41,72 ; 83,44$ e 125,16 $\mathrm{mg} \mathrm{kg}{ }^{-1}$ de $\mathrm{P}_{2} \mathrm{O}_{5}$, correspondentes a $0,100,200 \mathrm{e}$ $300 \mathrm{~kg} \mathrm{ha}^{-1}$ ), utilizando como fonte ureia e superfosfato triplo, respectivamente. Estes foram arranjados em esquema fatorial $4 \times 4$, em delineamento de blocos casualizados, com quatro repetições. A adubação complementar consistiu-se de $25 \mathrm{mg} \mathrm{kg}^{-1} \mathrm{~K}_{2} \mathrm{O}$, tendo como fonte o $\mathrm{KCl}$, e $150 \mathrm{mg} \mathrm{kg}^{-1}$ do formulado comercial de micronutrientes FTE-BR12, aplicados cinco dias antes da semeadura, juntamente com o fósforo. A adubação nitrogenada foi parcelada, sendo um terço 40 dias após a emergência e o restante 30 dias após a primeira adubação nitrogenada.

Aos 210 dias após a semeadura as plantas foram colhidas, separadas em parte aérea e raiz, procedendo-se a secagem do material em estufa de circulação forçada de ar a $60^{\circ} \pm 5^{\circ} \mathrm{C}$. Após obtenção de massa constante, o material foi pesado e moído para determinação dos teores de macro e micronutrientes (MALAVOLTA et al., 1997). A partir desses teores, determinou-se o conteúdo dos nutrientes com base na massa seca multiplicada pelo teor do nutriente.

A partir da massa seca e do conteúdo dos nutrientes na planta, foram calculados os seguintes índices de eficiência nutricional:

Eficiência de absorcão $\left(\mathrm{mg} \mathrm{g}^{-1}\right)=\frac{\text { (conteúdo total do nutriente na planta) }}{(\text { massa seca de raízes })}$

(SWIADER et al., 1994)

Eficiência de uso $\left(\mathrm{g}^{2} \mathrm{mg}^{-1}\right)=\frac{(\text { massa seca total produzida })^{2}}{(\text { conteúdo total do nutriente na planta })}$

(SIDDIQI e GLASS, 1981)

Os dados foram submetidos à análise de variância pelo teste $\mathrm{F} \mathrm{a} 5 \%$ de probabilidade e para o caso de diferenças significativas realizou-se análise de regressão utilizando-se programa computacional SAEG 9.0 (RIBEIRO JÚNIOR; MELO, 2009). Os gráficos foram ajustados por meio do programa Sigma Plot 9.0.

\section{RESULTADOS E DISCUSSÃO}

Houve interação significativa entre as doses de $\mathrm{N}$ e $\mathrm{P}$ para massa seca da parte aérea (MSPA) e da raiz (MSR), sendo obtido máximo 
de 7,14 g/planta de MSPA com as maiores doses de $\mathrm{N}$ e $\mathrm{P}$, e 2,32 g/planta de MSR com a dose de $125,16 \mathrm{mg} \mathrm{kg}^{-1}$ de $\mathrm{P}$ e $0 \mathrm{mg} \mathrm{kg}^{-1}$ de $\mathrm{N}$ (Tabela 1$)$. O $\mathrm{P}$ foi o principal nutriente a promover acúmulo de biomassa, indicando sua importância nos estádios iniciais de crescimento da espécie. Isso porque, no metabolismo vegetal, o P está envolvido na síntese de açúcares fosfatados e fosfolipídios (TAIZ;
ZEIGER, 2013), ácidos nucleicos e coenzimas (MARSCHNER, 1995). Por fazer parte da formação de compostos orgânicos, desempenha importante papel na transferência de energia da célula, na respiração e na fotossíntese (ANGHINONI; BISSANI, 2004).

Os teores dos nutrientes $\mathrm{P}, \mathrm{K}, \mathrm{Ca}, \mathrm{Cu}$, Mn e Zn na parte aérea e N, P, K, Ca, Mg e Fe na

TABELA 1: Equações de regressão para massa seca da parte aérea e de raiz de mudas de barbatimão aos 210 dias após a semeadura, em função da adubação nitrogenada e fosfatada. UFGD, Dourados - MS, 2009.

TABLE 1: Regression equations for dry weight of shoot and root of seedlings barbatimão at 210 days after sowing as a function of phosphorus and nitrogen fertilization. UFGD, Dourados - MS, 2009.

\begin{tabular}{cccr}
\hline Característica & Equação & Massa máxima & $\mathrm{R}^{2}$ \\
\hline Massa seca da parte aérea & $\hat{\mathrm{y}}=0,949+0,031 \mathrm{~N}+0,009 \mathrm{P}+0,0002 \mathrm{P}^{2}$ & $7,14 \mathrm{~g} /$ planta & 0,89 \\
Massa seca de raiz & $\hat{\mathrm{y}}=0,561+0,012 \mathrm{~N}+0,0053 \mathrm{P}+0,00007 \mathrm{P}^{2}-0,0002 \mathrm{NP}$ & $2,32 \mathrm{~g} /$ planta & 0,71 \\
\hline
\end{tabular}

Em que: $\mathrm{N}=$ nitrogênio; $\mathrm{P}$ = fósforo; $\mathrm{R}^{2}=$ coeficiente de regressão.

TABELA 2: Equações de regressão para teor de nutrientes, teores máximos obtidos e suas doses determinantes, na parte aérea e na raiz de mudas de barbatimão aos 210 dias após a semeadura, em função da adubação nitrogenada e fosfatada. UFGD, Dourados - MS, 2009.

TABLE 2: Regression equations for nutrient concentration, maximum concentrations obtained and their determining doses in shoot and root of barbatimão seedlings at 210 days after sowing as a function of phosphorus and nitrogen fertilization. UFGD, Dourados - MS, 2009.

\begin{tabular}{|c|c|c|c|c|c|}
\hline \multirow[t]{2}{*}{ Nutriente $^{1}$} & Equação & $\mathrm{R}^{2}$ & \multirow{2}{*}{$\begin{array}{c}\text { Teor } \\
\text { máximo }\end{array}$} & \multicolumn{2}{|c|}{$\begin{array}{c}\text { Dose } \\
\text { determinante }\end{array}$} \\
\hline & \multicolumn{2}{|l|}{ Parte aérea } & & $\mathrm{N}$ & $\mathrm{P}$ \\
\hline $\mathrm{N}$ & $\hat{\mathrm{y}}=29,314-0,433 \mathrm{~N}+0,0066 \mathrm{~N}^{2}$ & 0,76 & 28,02 & 62,46 & - \\
\hline $\mathrm{P}$ & $\hat{\mathrm{y}}=0,515+0,0048 \mathrm{~N}+0,0066 \mathrm{P}$ & 0,87 & 1,64 & 62,46 & 125,16 \\
\hline $\mathrm{K}$ & $\hat{y}=4,131+0,0656 \mathrm{~N}-0,00075 \mathrm{~N}^{2}-0,0045 \mathrm{P}$ & 0,62 & 5,56 & 43,73 & 00,00 \\
\hline $\mathrm{Ca}$ & $\hat{\mathrm{y}}=4,6014-0,0383 \mathrm{~N}+0,0005 \mathrm{~N}^{2}+0,0139 \mathrm{P}$ & 0,74 & 6,34 & 00,00 & 125,16 \\
\hline $\mathrm{Mg}$ & $\hat{\mathrm{y}}=1,028+0,003 \mathrm{P}-0,000007 \mathrm{P}^{2}$ & 0,78 & 1,29 & - & 125,16 \\
\hline $\mathrm{Cu}$ & $\bar{y}=4,06$ & s/aj. & - & - & - \\
\hline $\mathrm{Mn}$ & $\bar{y}=36,15$ & s/aj. & - & - & - \\
\hline $\mathrm{Fe}$ & $\hat{y}=529+5,267 \mathrm{~N}-0,055 \mathrm{~N}^{2}$ & 0,99 & 655,5 & 47,88 & - \\
\hline \multirow[t]{2}{*}{$\mathrm{Zn}$} & $\overline{\mathrm{y}}=24,579+0,1883 * \mathrm{~N}-0,0363 \mathrm{P}$ & 0,64 & 36,34 & 62,46 & 00,00 \\
\hline & Raiz & & & & \\
\hline $\mathrm{N}$ & $\overline{\mathrm{y}}=14,11$ & s/aj. & - & - & - \\
\hline $\mathrm{P}$ & $\hat{\mathrm{y}}=0,099+0,097 \mathrm{~N}-0,0009 \mathrm{~N}^{2}+0,013 \mathrm{P}-0,0001 \mathrm{P}^{2}-0,0008 \mathrm{NP}$ & 0,94 & 2,71 & 53,88 & 00,00 \\
\hline $\mathrm{K}$ & $\bar{y}=4,05$ & s/aj. & - & - & - \\
\hline $\mathrm{Ca}$ & $\hat{\mathrm{y}}=0,9646+0,047 \mathrm{~N}-0,0005 \mathrm{~N}^{2}+0,007 \mathrm{P}-0,00004 \mathrm{P}^{2}$ & 0,85 & 2,37 & 47,00 & 87,50 \\
\hline $\mathrm{Mg}$ & $\hat{y}=0,934+0,0209 \mathrm{~N}-0,0003 \mathrm{~N}^{2}-0,0015 \mathrm{P}$ & 0,81 & 1,29 & 34,83 & 00,00 \\
\hline $\mathrm{Cu}$ & $\bar{y}=12,15$ & s/aj. & - & - & - \\
\hline $\mathrm{Mn}$ & $\bar{y}=15,63$ & s/aj. & - & - & - \\
\hline $\mathrm{Fe}$ & $\hat{\mathrm{y}}=432,588+10,988 \mathrm{~N}+3,541 \mathrm{P}$ & 0,70 & $1.562,1$ & 62,46 & 125,16 \\
\hline $\mathrm{Zn}$ & $\overline{\mathrm{y}}=13,36$ & s/aj. & - & - & - \\
\hline
\end{tabular}

Em que: ${ }^{1}$ Macronutrientes em $\mathrm{g} \mathrm{kg}^{-1}$; Micronutrientes em $\mathrm{mg} \mathrm{kg}^{-1} ; \mathrm{N}=$ nitrogênio; $\mathrm{P}=$ fósforo; $\mathrm{K}=$ potássio; $\mathrm{Ca}$ = cálcio; $\mathrm{Mg}$ = magnésio; $\mathrm{Cu}=$ cobre; $\mathrm{Mn}=$ manganês; $\mathrm{Fe}=$ ferro; $\mathrm{Zn}=$ zinco; $\mathrm{R}^{2}=$ coeficiente de regressão; $\mathrm{s} /$ aj.= sem ajuste da regressão. 
raiz, foram influenciados significativamente pela interação entre as doses de $\mathrm{N}$ e $\mathrm{P}$ (Tabela 2). Na parte aérea das mudas, os nutrientes $\mathrm{N}$ e $\mathrm{Fe}$ foram influenciados somente pelo efeito isolado das doses de $\mathrm{N}$ e o teor de $\mathrm{Mg}$ pelo efeito isolado das doses de P. Não houve ajuste de modelo de regressão para $\mathrm{Cu}$ e $\mathrm{Mn}$ na parte aérea e para $\mathrm{N}, \mathrm{K}, \mathrm{Cu}, \mathrm{Mn} \mathrm{Zn}$ na raiz, sendo apresentados seus valores médios. De maneira geral, o $\mathrm{N}$ induziu aumento do teor de nutrientes, no entanto, o P induziu aumento do crescimento da planta, o que sugere um efeito de diluição na concentração dos nutrientes absorvidos em relação ao aumento das doses de P.

Comparados aos teores que Epstein e Bloom (2006) consideram adequados, os nutrientes $\mathrm{P}, \mathrm{K}, \mathrm{Mg}, \mathrm{Cu}$ e $\mathrm{Mn}$ encontram-se abaixo do nível de suficiência na parte aérea, embora a planta não tenha apresentado sintomas de deficiência. Segundo Haridasan (2008), os conceitos de deficiência de nutrientes e toxicidade, bem estabelecidos na agricultura, não devem ser estendidos às plantas nativas em ecossistemas naturais, indiscriminadamente, pois muitas delas são resistentes ou tolerantes às condições edáficas consideradas desfavoráveis às plantas cultivadas.

Árvores isoladas de Stryphnodendron guianense sob pastagens cultivadas na Amazônia Ocidental apresentaram teor foliar de macronutrientes semelhante ao da parte aérea das mudas de barbatimão deste estudo, sendo $21,8 \mathrm{~g}$ $\mathrm{kg}^{-1}$ de $\mathrm{N} ; 1,24 \mathrm{~g} \mathrm{~kg}^{-1}$ de P; $6 \mathrm{~g} \mathrm{~kg}^{-1}$ de $\mathrm{K} ; 7,8 \mathrm{~g}$ $\mathrm{kg}^{-1}$ de $\mathrm{Ca}$ e 3,93 $\mathrm{g} \mathrm{kg}^{-1}$ de $\mathrm{Mg}$ (ANDRADE et al., 2002). Em estudo sobre requerimento nutricional de mudas de Stryphnodendron adstringens, dentre outras espécies, em Latossolo VermelhoAmarelo, obteve-se, aos 245 dias após semeadura, teores de macronutrientes $\left(\mathrm{g} \mathrm{kg}^{-1}\right)$ de 20,2 de N; 0,78 de $\mathrm{P} ; 5,4$ de $\mathrm{K} ; 7,71$ de $\mathrm{Ca} ; 1,05$ de $\mathrm{Mg}$ no tratamento completo com calagem e 16,5 de $\mathrm{N}$, 0,43 de $\mathrm{P}, 1,15$ de $\mathrm{K}, 6,45$ de $\mathrm{Ca}$ e $0,83 \mathrm{~g} \mathrm{~kg}^{-1}$ de $\mathrm{Mg}$ na testemunha; no tratamento completo com ausência de calagem, a absorção de N, K e Mg foi prejudicada (CARLOS, 2009). Em comparação aos trabalhos de Andrade et al. (2002) e Carlos (2009), as mudas de Stryphnodendron polyphyllum deste estudo apresentaram-se mais exigentes em $\mathrm{N}$, do que Stryphnodendron guianense e Stryphnodendron adstringens, respectivamente.

O conteúdo de todos os nutrientes, na parte aérea e na raiz, foi influenciado significativamente pela interação entre as doses de $\mathrm{N}$ e P. As máximas doses proporcionaram maior conteúdo de macronutrientes na parte aérea, exceto $\mathrm{N}$ e $\mathrm{K}$, que foram obtidos com dose de $\mathrm{N}$ de 60,52 e $54,80 \mathrm{mg}$ $\mathrm{kg}^{-1}$, respectivamente, e máxima de $\mathrm{P}$ (Figura 1, Tabela 3).

Observa-se que, na parte aérea das mudas, houve efeito linear das doses de P sobre o conteúdo de quase todos os nutrientes, indicando que a dose de $125,16 \mathrm{mg} \mathrm{kg}^{-1}$ não foi suficiente em propiciar máxima resposta. Resultado semelhante foi obtido por Santos et al. (2008) em que o maior nível de adubação fosfatada (equivalente a $200 \mathrm{~kg} \mathrm{ha}^{-1} \mathrm{de} \mathrm{P}$ ) em mudas de mogno (Swietenia macrophylla King) esteve aquém do suprimento ideal para a expressão do máximo potencial da espécie.

Em virtude do maior investimento no crescimento da parte aérea, observado em vários estudos (MARQUES et al., 2006; BRONDANI et al., 2008; FERNANDES et al., 2008), é comum que ocorra maior demanda nutricional para esta parte da planta, ainda mais com fornecimento extra de nutrientes. Quando da ausência de adubação nitrogenada e fosfatada houve maior demanda de $\mathrm{N}$ e Ca para parte aérea em relação à raiz, da ordem de 7 a 20 vezes maior, respectivamente. Comparandose ao maior conteúdo de nutrientes obtidos nas diferentes partes da planta (ver Tabela 3), a demanda de $\mathrm{N}$ para parte aérea foi de apenas 0,8 vezes em relação à da raiz.

$\mathrm{Na}$ raiz das mudas do barbatimão houve decréscimo no conteúdo dos macronutrientes conforme aumento da dose de $\mathrm{N}$, especialmente o $\mathrm{K}$, o qual apresentou maior conteúdo com a menor dose de N (Figura 2, Tabela 3). O conteúdo de N na raiz foi maior comparado ao da parte aérea, quando isso ocorre é possível que seja em função do armazenamento de $\mathrm{N}$ amoniacal, indicando que essa parte da planta pode ser utilizada como destino de parte do excesso de amônio absorvido, contribuindo para amenizar os possíveis efeitos tóxicos desse íon sobre outros órgãos da planta, assim como observado por Cruz et al. (2006). Mesmo não sendo objetivo de estudo, observaram-se nódulos radiculares nas raízes das mudas de barbatimão, independentemente da dose de $\mathrm{N}$ aplicada. Leguminosas arbóreas tendem a formar nódulos nas raízes devido à associação simbiótica com bactérias do solo, as quais reduzem o $\mathrm{N}$ atmosférico - a amônia (BROUGHTON et al., 2003), o que também pode ter influenciado no aumento do conteúdo de $\mathrm{N}$ na raiz.

Estudos sobre nutrição mineral de espécies arbóreas nativas demonstram que estas respondem positivamente à fertilização, principalmente em 

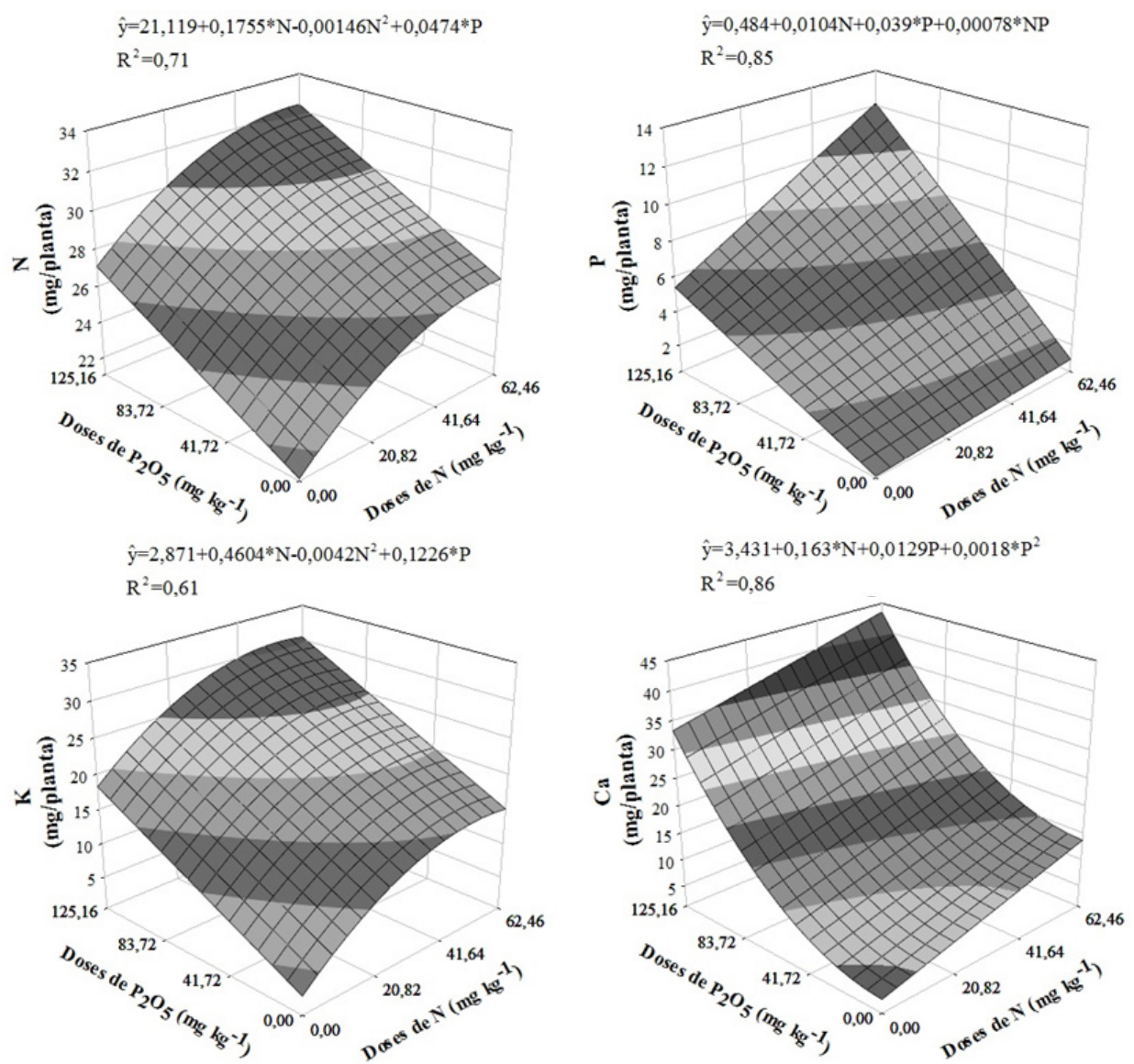

$\hat{\mathrm{y}}=0,421+0,036^{*} \mathrm{~N}+0,0473^{*} \mathrm{P}$

$\mathrm{R}^{2}=0,87$

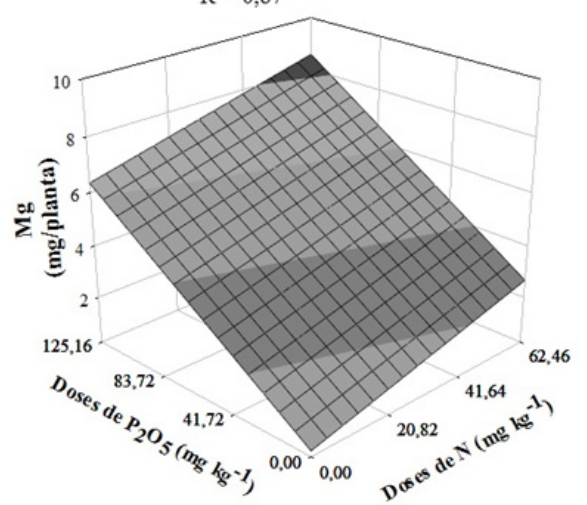

FIGURA 1: Conteúdo de macronutrientes na parte aérea de mudas de barbatimão aos 210 dias após a semeadura em função da adubação nitrogenada e fosfatada. UFGD, Dourados - MS, 2009. $\mathrm{N}=$ nitrogênio; $\mathrm{P}=$ fósforo; $\mathrm{K}=$ potássio; $\mathrm{Ca}=$ cálcio; $\mathrm{Mg}=$ magnésio.

FIGURE 1: Macronutrients content in shoots of barbatimão seedlings at 210 days after sowing as a function of phosphorus and nitrogen fertilization. UFGD, Dourados - MS, 2009. N = nitrogen; $\mathrm{P}=$ phosphorus; $\mathrm{K}=$ potassium; $\mathrm{Ca}=$ calcium; $\mathrm{Mg}=$ magnesium

relação ao nitrogênio e fósforo. Utilizando a técnica do elemento faltante na nutrição mineral de Peltophorum dubium, Venturin et al. (1999) verificaram que a absorção de nutrientes foi mais prejudicada quando da omissão de $\mathrm{N}$ e $\mathrm{P}$, comparando-se à testemunha. No tratamento completo, aos 96 DAT, utilizando as doses de 150 mg $\mathrm{kg}^{-1}$ de $\mathrm{N}$ e $120 \mathrm{mg} \mathrm{kg}^{-1}$ de $\mathrm{P}$, o conteúdo de macronutrientes (mg/planta) na parte aérea das mudas foi: 260,3 (N), 12,2 (P), 87,8 (K), 74,9 (Ca) e 16,4 (Mg). Em mudas de Carapa guianensis, após seis meses de cultivo sob doses crescentes de P, 
TABELA 3: Conteúdo máximo de macro e micronutrientes em mudas de barbatimão aos 210 dias após a semeadura em função da adubação nitrogenada e fosfatada. UFGD, Dourados - MS, 2009.

TABLE 3: Maximum macro and micronutrients content in barbatimão seedlings at 210 days after sowing as a function of phosphorus and nitrogen fertilization. UFGD, Dourados - MS, 2009.

\begin{tabular}{|c|c|c|c|c|c|c|c|}
\hline \multicolumn{8}{|c|}{ Conteúdo de macronutrientes (mg/planta) } \\
\hline \multicolumn{4}{|c|}{ Parte aérea } & \multicolumn{4}{|c|}{ Raiz } \\
\hline \multirow{2}{*}{ Nutriente } & \multirow{2}{*}{ Conteúdo } & \multicolumn{2}{|c|}{ Dose determinante } & \multirow{2}{*}{ Nutriente } & \multirow{2}{*}{ Conteúdo } & \multicolumn{2}{|c|}{ Dose determinante } \\
\hline & & $\mathrm{N}$ & $\mathrm{P}$ & & & $\mathrm{N}$ & $\mathrm{P}$ \\
\hline $\mathrm{N}$ & 32,33 & 60,52 & 125,16 & $\mathrm{~N}$ & 37,37 & 22,20 & 125,16 \\
\hline $\mathrm{P}$ & 12,27 & 62,46 & 125,16 & $\mathrm{P}$ & 05,38 & 35,96 & 125,16 \\
\hline $\mathrm{K}$ & 30,83 & 54,80 & 125,16 & $\mathrm{~K}$ & 10,38 & 00,00 & 125,16 \\
\hline $\mathrm{Ca}$ & 43,42 & 62,46 & 125,16 & $\mathrm{Ca}$ & 04,46 & 38,75 & 125,16 \\
\hline $\mathrm{Mg}$ & 08,59 & 62,46 & 125,16 & $\mathrm{Mg}$ & 02,45 & 34,98 & 125,16 \\
\hline \multicolumn{8}{|c|}{ Conteúdo de micronutrientes ( $\mu \mathrm{g} /$ planta) } \\
\hline \multicolumn{4}{|c|}{ Parte aérea } & \multicolumn{4}{|c|}{ Raiz } \\
\hline \multirow{2}{*}{ Nutriente } & \multirow{2}{*}{ Conteúdo } & \multicolumn{2}{|c|}{ Dose determinante } & \multirow{2}{*}{ Nutriente } & \multirow{2}{*}{ Conteúdo } & \multicolumn{2}{|c|}{ Dose determinante } \\
\hline & & $\mathrm{N}$ & $\mathrm{P}$ & & & $\mathrm{N}$ & $\mathrm{P}$ \\
\hline $\mathrm{Cu}$ & 22,43 & 62,46 & 125,16 & $\mathrm{Cu}$ & 27,78 & 16,13 & 125,16 \\
\hline $\mathrm{Fe}$ & 4406,14 & 62,46 & 125,16 & $\mathrm{Fe}$ & 2693,69 & 62,46 & 125,16 \\
\hline $\mathrm{Mn}$ & 253,13 & 62,46 & 125,16 & $\mathrm{Mn}$ & 23,20 & 00,00 & 125,16 \\
\hline $\mathrm{Zn}$ & 260,36 & 62,46 & 125,16 & $\mathrm{Zn}$ & 29,52 & 22,81 & 125,16 \\
\hline
\end{tabular}

Em que: $\mathrm{N}=$ nitrogênio; $\mathrm{P}=$ fósforo; $\mathrm{K}=$ potássio; $\mathrm{Ca}=$ cálcio; $\mathrm{Mg}=$ magnésio; $\mathrm{Cu}=$ cobre; $\mathrm{Mn}=$ manganês; $\mathrm{Fe}=$ ferro; $\mathrm{Zn}=$ zinco.

Neves et al. (2004) observaram que os elementos em estudo que mais se acumularam na parte aérea (mg/planta) seguem a seguinte ordem decrescente: N $(254,3) ; \mathrm{Ca}(133,5) ; \mathrm{K}(106,5) ; \mathrm{Mg}(17,9) ; \mathrm{S}$ $(16,3)$ e $\mathrm{P}(6,4)$, esses valores foram obtidos com doses de P variando de 241 a 287,5 $\mathrm{mg} \mathrm{dm}^{-3}$.

Gonçalves et al. (2012), estudando a nutrição de mudas da leguminosa arbórea Anadenanthera macrocarpa (angico-vermelho) em diferentes tipos de solo, observaram comportamento distinto em relação às doses de nutrientes aplicadas. Em Latossolo Vermelho-Amarelo distrófico, de textura argilosa, as mudas de angico acumularam mais $\mathrm{N}$ e $\mathrm{P}$ na raiz, independentemente das doses aplicadas. Com a menor dose de $\mathrm{N}\left(50 \mathrm{mg} \mathrm{dm}^{-3}\right)$, o conteúdo de $\mathrm{N}$ foi 39,23 mg/planta na raiz e 33,16 $\mathrm{mg} /$ planta na parte aérea; com a maior dose (200 $\mathrm{mg} \mathrm{dm}{ }^{-3}$ ), o conteúdo de $\mathrm{N}$ passou a $75,1 \mathrm{mg} /$ planta na raiz e 56,4 mg/planta na parte aérea. A aplicação da menor dose de $\mathrm{P}\left(150 \mathrm{mg} \mathrm{dm}^{-3}\right)$ proporcionou conteúdo de $\mathrm{P}$ na raiz de $0,91 \mathrm{mg} / \mathrm{planta} \mathrm{e} 0,86$ $\mathrm{mg} /$ planta na parte aérea, e com a maior dose $(600$ $\mathrm{mg} \mathrm{dm}{ }^{-3}$ ), o conteúdo de $\mathrm{P}$ passou a $5,2 \mathrm{mg} /$ planta na raiz e $3,98 \mathrm{mg} /$ planta na parte aérea. As mudas de barbatimão, no presente estudo, mostraramse mais exigentes em $\mathrm{P}$ e semelhantes quanto ao requerimento em $\mathrm{N}$ comparado ao angico-vermelho.

$\mathrm{O}$ conteúdo de micronutrientes na parte aérea aumentou em função das doses de $\mathrm{N}$ e $\mathrm{P}$ (Figura 3) e reduziu na raiz, exceto Fe (Figura 4). O $\mathrm{N}$ foi responsável pela queda no conteúdo de $\mathrm{Cu}, \mathrm{Zn}$ e Mn na raiz, quando combinado com as doses de P. Com o maior crescimento da planta, especialmente da parte aérea, a demanda por nutrientes é maior, assim, considerando o envolvimento dos micronutrientes $\mathrm{Cu}$ e $\mathrm{Mn}$ no transporte de elétrons na fotossíntese e o Zn como ativador enzimático de diversas reações (TAIZ; ZEIGER, 2013), possivelmente foi fator determinante para redução destes na raiz.

$\mathrm{Na}$ ausência de adubação, diferente dos outros micronutrientes, o $\mathrm{Cu}$ acumulou-se mais na raiz em relação à parte aérea e foi fortemente influenciado pelo aumento das doses de $\mathrm{P}$, indicando que tanto a absorção quanto a translocação de $\mathrm{Cu}$ foi favorecida em relação à adubação. Silva et al. (2011), estudando a tolerância de três espécies florestais nativas ao excesso de cobre em Argissolo Vermelho-Amarelo distrófico, verificaram que a espécie Peltophorum dubium apresenta tendência de armazenamento de $\mathrm{Cu}$ nas raízes e baixa translocação para a parte aérea.

Quanto aos índices de eficiência nutricional, houve interação significativa entre as doses de $\mathrm{N}$ e $\mathrm{P}$, no entanto, não foi possível ajustar modelo de regressão para alguns nutrientes 

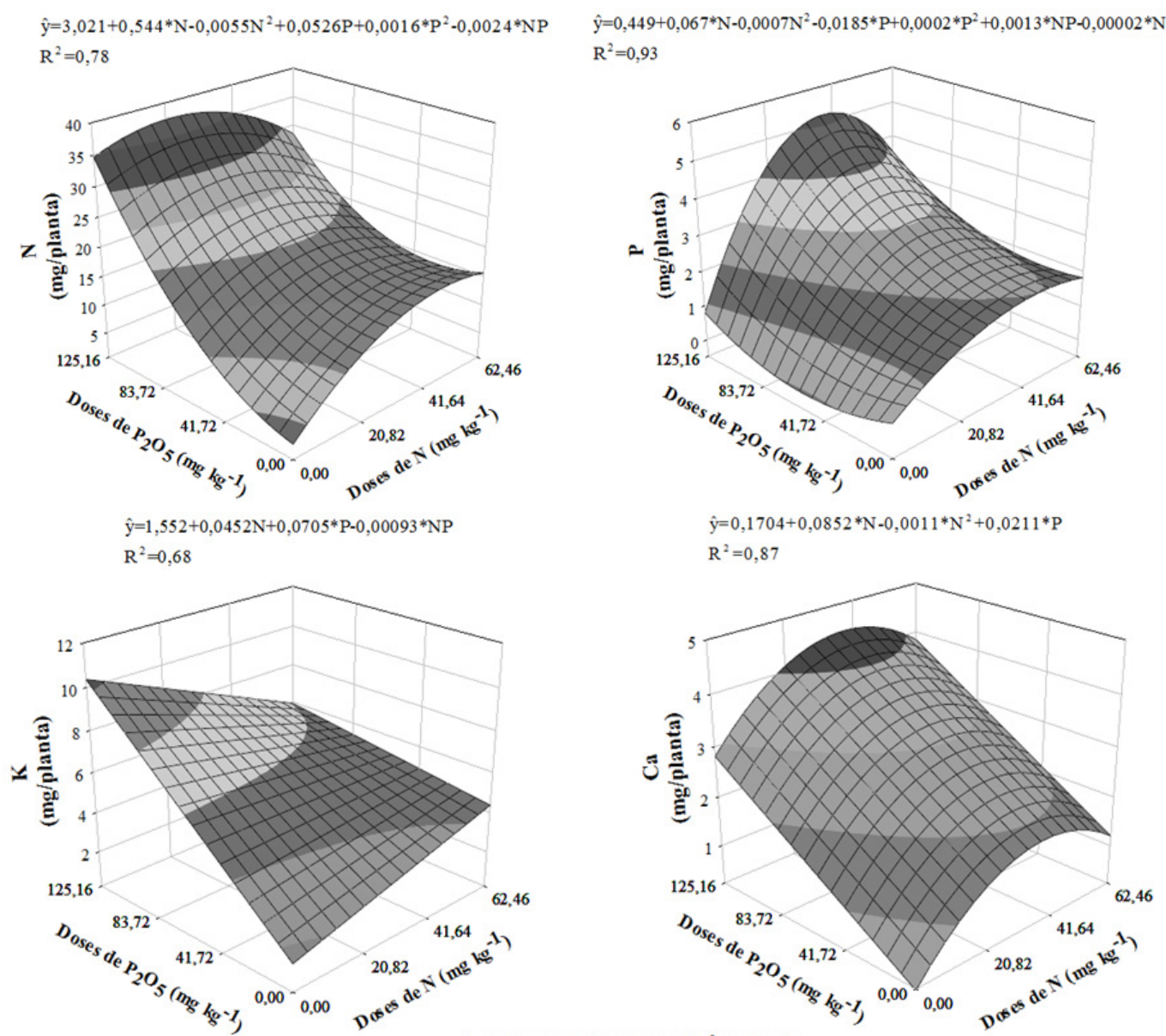

$\hat{\mathrm{y}}=0,362+0,0424 * \mathrm{~N}-0,00059 * \mathrm{~N}^{2}+0,0107 * \mathrm{P}$

$\mathrm{R}^{2}=0,82$

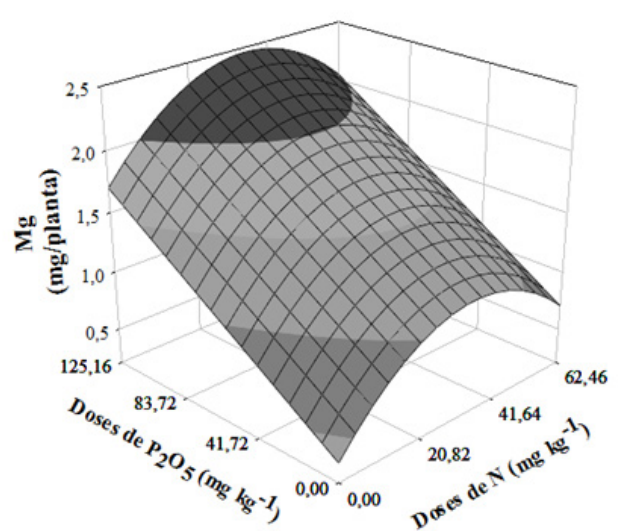

FIGURA 2: Conteúdo de macronutrientes na raiz de mudas de barbatimão aos 210 dias após a semeadura em função da adubação nitrogenada e fosfatada. UFGD, Dourados - MS, 2009. N = nitrogênio; $\mathrm{P}=$ fósforo; $\mathrm{K}=$ potássio; $\mathrm{Ca}=$ cálcio; $\mathrm{Mg}=$ magnésio

FIGURE 2: Macronutrients content in roots of barbatimão seedlings at 210 days after sowing as a function of phosphorus and nitrogen fertilization. UFGD, Dourados - MS, 2009. N = nitrogen; $\mathrm{P}=$ phosphorus $\mathrm{K}=$ potassium $; \mathrm{Ca}=$ calcium; $\mathrm{Mg}=$ magnesium

(Tabela 4). Os valores máximos para eficiência de absorção de $\mathrm{P}\left(8,59 \mathrm{mg} \mathrm{g}^{-1}\right), \mathrm{Ca}\left(26,86 \mathrm{mg} \mathrm{g}^{-1}\right), \mathrm{Mg}$ $\left(6,63 \mathrm{mg} \mathrm{g}^{-1}\right)$, Mn $\left(131,83 \mu \mathrm{g} \mathrm{g}^{-1}\right)$, Fe $(4.401,52$ $\left.\mu \mathrm{g} \mathrm{g}^{-1}\right)$ e $\mathrm{Zn}\left(168,5 \mu \mathrm{g} \mathrm{g}^{-1}\right)$ foram alcançados com a maior dose de $\mathrm{N}$ e dose de $\mathrm{P}$ variando de 65,56 a $104,5 \mathrm{mg} \mathrm{kg}^{-1}$; a máxima eficiência de absorção 

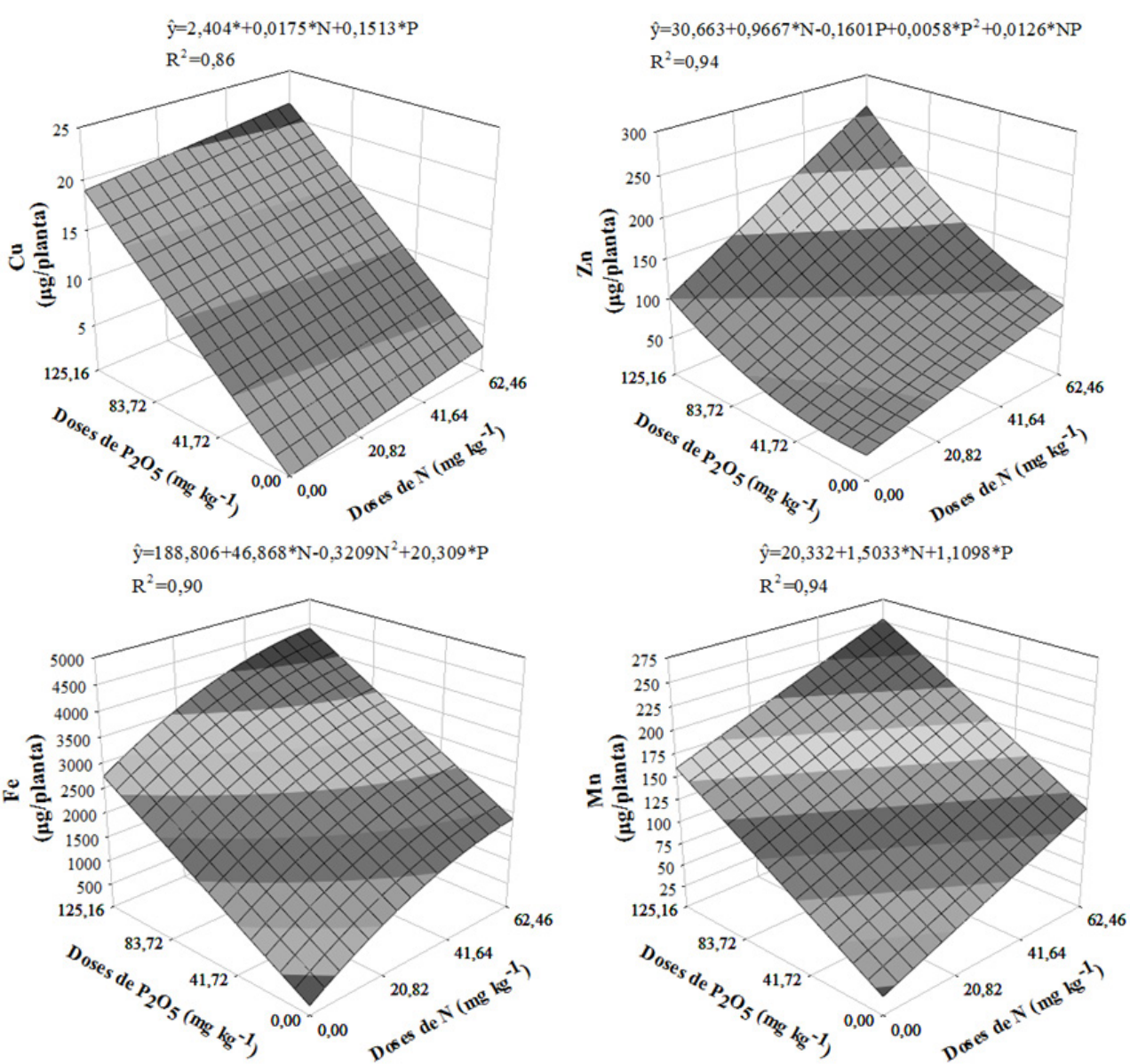

FIGURA 3: Conteúdo de micronutrientes na parte aérea de mudas de barbatimão aos 210 dias após a semeadura em função da adubação nitrogenada e fosfatada. UFGD, Dourados - MS, 2009. $\mathrm{Cu}=$ cobre; $\mathrm{Mn}=$ manganês; $\mathrm{Fe}=$ ferro; $\mathrm{Zn}=$ zinco.

FIGURE 3: Micronutrients content in shoots of barbatimão seedlings at 210 days after sowing as a function of phosphorus and nitrogen fertilization. UFGD, Dourados - MS, 2009. $\mathrm{Cu}=$ copper; $\mathrm{Mn}=$ manganese; $\mathrm{Fe}=$ iron; $\mathrm{Zn}=$ zinc.

de $\mathrm{N}\left(49,77 \mathrm{mg} \mathrm{g}^{-1}\right)$ foi obtida com somente a maior dose de N. As maiores doses de $\mathrm{N}$ e $\mathrm{P}$ proporcionaram máxima eficiência de uso de $\mathrm{K}$ (1,99 $\left.\mathrm{mg} \mathrm{g}^{-1}\right)$, enquanto a de $\mathrm{Zn}\left(0,35 \mu \mathrm{g} \mathrm{g}^{-1}\right)$ foi obtida com somente a maior dose de P. As mudas de barbatimão mostraram-se mais eficientes em absorver $\mathrm{N}$ e $\mathrm{Ca}$ e utilizar $\mathrm{P}$ e $\mathrm{Mg}$. A maior eficiência de absorção e acúmulo de $\mathrm{Ca}$ favorecidos pela adubação nitrogenada provavelmente está relacionada com a formação de pares iônicos entre o $\mathrm{Ca}$ e o nitrato. Maiores teores de nitrato contribuem na dinâmica dos nutrientes catiônicos no solo, pois o ânion $\mathrm{NO}_{3}^{-}$é considerado íon acompanhante de $\mathrm{Ca}^{2+}, \mathrm{Mg}^{2+}, \mathrm{K}^{+}$e $\mathrm{Al}^{3+}$ (ROSOLEM; FOLONI; OLIVEIRA, 2003) e, assim, possivelmente, houve melhorias na absorção. O Ca tem papel fundamental na estabilidade de biomembranas, na divisão e desenvolvimento celular, na estrutura da parede celular e na formação da lamela média (HEPLER, 2005), consequentemente, sua maior disponibilidade no início de crescimento vegetal favorece até mesmo a absorção de outros nutrientes necessários ao desenvolvimento da planta.

Comparados ao conteúdo, o $\mathrm{N}$ e o $\mathrm{Ca}$ foram os nutrientes mais acumulados nos tecidos da planta, contudo, os que apresentaram menor valor (P e Mg) foram os nutrientes utilizados com maior eficácia. De acordo com Von Wirén et al. (1997), a absorção de $\mathrm{N}$ por meio da membrana plasmática é realizada por dois tipos de carregadores: os de baixa afinidade que operam quando a concentração externa de $\mathrm{N}$ é alta e não são sujeitos à regulação e os carregadores de alta afinidade que atuam sob baixas concentrações externas de $\mathrm{N}$ e podem ser 

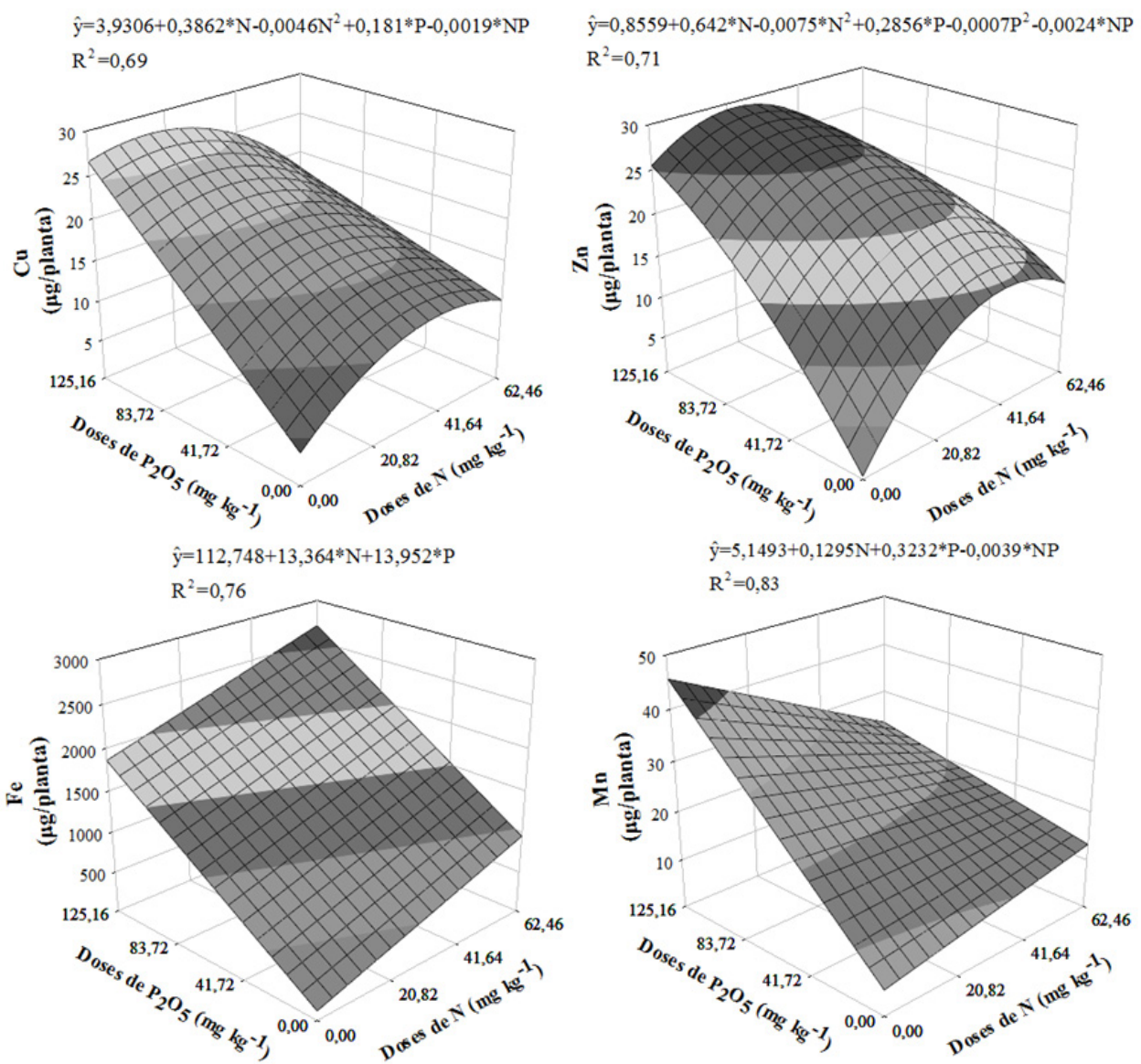

FIGURA 4: Conteúdo de micronutrientes na raiz de mudas de barbatimão aos 210 dias após a semeadura em função da adubação nitrogenada e fosfatada. UFGD, Dourados - MS, 2009. $\mathrm{Cu}=$ cobre; $\mathrm{Mn}=$ manganês; $\mathrm{Fe}=$ ferro; $\mathrm{Zn}=$ zinco.

FIGURE 4: Micronutrients content in roots of barbatimão seedlings at 210 days after sowing as a function of phosphorus and nitrogen fertilization. UFGD, Dourados - MS, 2009. $\mathrm{Cu}=$ copper; $\mathrm{Mn}=$ manganese; $\mathrm{Fe}=$ iron; $\mathrm{Zn}=$ zinc.

induzidos pela exposição ao N. Já a eficiência da utilização do $\mathrm{N}$ adicionado ao solo está relacionada ao grau de recuperação desse elemento pelas plantas, considerando as perdas que geralmente ocorrem (BREDEMEIER; MUNDSTOCK, 2000). Segundo esses autores, menos de $50 \%$ do $\mathrm{N}$ aplicado sob a forma de fertilizante é utilizado pelas culturas. Mesmo sendo baixa a eficiência de uso de $\mathrm{N}$ pelo barbatimão, no presente estudo, tanto o teor quanto a eficiência de uso foram maiores do que grandes culturas como soja e feijão em estudo realizado por Procópio et al. (2004), quando da ausência de adubação nitrogenada. Diante disso, pode-se afirmar que o barbatimão, dentre outras plantas nativas do Cerrado, é uma espécie bem adaptada às condições de baixa fertilidade.

A alta eficiência de uso de $\mathrm{P}$ e $\mathrm{Mg}$ está relacionada ao papel que estes desempenham no metabolismo vegetal. Muitas reações acontecem via dependência entre esses elementos e iniciam-se com o papel do Mg na absorção de P pelas plantas, facilitando sua entrada como íon acompanhante (VITTI; LIMA; CICARONE, 2006). As reações de transferência de energia necessitam de $\mathrm{Mg}$, pois a maior parte do ATP presente na célula está complexado com Mg (MARTINOIA; MASSONNEAU; FRANGNE, 2000). Essa relação entre esses dois nutrientes pode explicar o maior acúmulo e eficiência de uso de $\mathrm{Mg}$ quando houve aumento das doses de $\mathrm{P}_{2} \mathrm{O}_{5}$.

Em solos distróficos como os de Cerrado é comum encontrar e associar baixas concentrações de nutrientes nas folhas das espécies nativas à baixa fertilidade dos solos, o que reflete em adaptações 
TABELA 4: Eficiência de absorção e de uso de nutrientes em mudas de barbatimão aos 210 dias após a semeadura, em função da adubação fosfatada e nitrogenada. UFGD, Dourados - MS, 2009.

TABLE 4: Uptake and use efficiency of nutrients in barbatimão seedlings at 210 days after sowing as a function of phosphorus and nitrogen fertilization. UFGD, Dourados - MS, 2009.

\begin{tabular}{|c|c|c|c|c|c|}
\hline $\begin{array}{c}\text { Eficiência } \\
\text { absorção }\end{array}$ & Equação & $\mathrm{R}^{2}$ & $\begin{array}{c}\text { Eficiência } \\
\text { uso }\end{array}$ & Equação & $\mathrm{R}^{2}$ \\
\hline $\mathrm{N}$ & $\hat{y}=44,611+0,0826 \mathrm{~N}-0,138 \mathrm{P}$ & 0,52 & $\mathrm{~N}$ & $\overline{\mathrm{y}}=0,680$ & s/aj. \\
\hline $\mathrm{P}$ & $\hat{\mathrm{y}}=0,661+0,077 \mathrm{~N}+0,079 \mathrm{P}-0,0005 \mathrm{P}^{2}$ & 0,70 & $\mathrm{P}$ & $\overline{\mathrm{y}}=4,444$ & s/aj. \\
\hline $\mathrm{K}$ & $\overline{\mathrm{y}}=18,516$ & $\mathrm{~s} / \mathrm{a}$ & $\mathrm{K}$ & $\hat{\mathrm{y}}=0,41+0,0063 \mathrm{~N}+0,0095 * \mathrm{P}$ & 0,59 \\
\hline $\mathrm{Ca}$ & $\hat{\mathrm{y}}=5,45+0,168 \mathrm{~N}+0,209 \mathrm{P}-0,001 \mathrm{P}^{2}$ & 0,51 & $\mathrm{Ca}$ & $\overline{\mathrm{y}}=1,241$ & s/aj. \\
\hline $\mathrm{Mg}$ & $\hat{\mathrm{y}}=2,166+0,038 \mathrm{~N}+0,0579 * \mathrm{P}-0,0004 \mathrm{P}^{2}$ & 0,51 & $\mathrm{Mg}$ & $\overline{\mathrm{y}}=4,718$ & s/aj. \\
\hline $\mathrm{Cu}$ & $\overline{\mathrm{y}}=23,965$ & s/aj. & $\mathrm{Cu}$ & $\overline{\mathrm{y}}=0,927$ & s/aj. \\
\hline $\mathrm{Mn}$ & $\overline{\mathrm{y}}=6,201+1,185 \mathrm{~N}+1,574 \mathrm{P}-0,012 \mathrm{P}^{2}$ & 0,55 & $\mathrm{Mn}$ & $\overline{\mathrm{y}}=0,180$ & s/aj. \\
\hline $\mathrm{Fe}$ & $\hat{y}=1144,7+33,722 \mathrm{~N}+28,541 \mathrm{P}-0,177 \mathrm{P}^{2}$ & 0,71 & $\mathrm{Fe}$ & $\overline{\mathrm{y}}=0,008$ & s/aj. \\
\hline $\mathrm{Zn}$ & $\overline{\mathrm{y}}=37,244+1,489 \mathrm{~N}+1,167 \mathrm{P}-0,0089 \mathrm{P}^{2}$ & 0,60 & $\mathrm{Zn}$ & $\hat{\mathrm{y}}=0,126-0,0004 \mathrm{~N}+0,0018 * \mathrm{P}$ & 0,53 \\
\hline
\end{tabular}

Em que: $\mathrm{N}=$ nitrogênio; $\mathrm{P}=$ fósforo; $\mathrm{K}=$ potássio; $\mathrm{Ca}=$ cálcio; $\mathrm{Mg}=$ magnésio; $\mathrm{Cu}=$ cobre; $\mathrm{Mn}=$ manganês; $\mathrm{Fe}=$ ferro; $\mathrm{Zn}=$ zinco; $\mathrm{R}^{2}$ = coeficiente de regressão; s/aj.= sem ajuste da regressão.

das plantas em utilizar de modo mais eficiente os nutrientes presentes em baixas concentrações. Dentre esses, o P é referido como o mais limitante às plantas devido às características de forte adsorção aos óxidos de ferro e alumínio da fração argila. $\mathrm{Na}$ planta, o P é determinante no crescimento, uma vez que tem considerável importância no metabolismo do carbono, bem como na formação de açúcares fosfatados.

\section{CONCLUSÕES}

A utilização conjunta de $\mathrm{N}$ e $\mathrm{P}$ propiciou melhor eficiência nutricional das mudas de barbatimão.

O barbatimão é uma espécie adaptada às condições de baixa fertilidade do solo.

\section{REFERÊNCIAS BIBLIOGRÁFICAS}

ANDRADE, C. M. S. et al. Árvores de baginha (Stryphnodendron guianense (Aubl.) Benth.) em ecossistemas de pastagens cultivadas na Amazônia Ocidental. Revista Brasileira de Zootecnia, Piracicaba, v. 31, n. 2, p. 574-582, 2002.

ANGHINONI, I.; BISSANI, C. A. Fósforo e adubos fosfatados. In: BISSANI, C. A. et al. (Ed.). Fertilidade dos solos e manejo de adubação de culturas. Porto Alegre: Gênesis, 2004. v. 1, p. 117-137.

BORGES FILHO, H. C.; FELFILI, J. M. Avaliação dos níveis de extrativismo da casca de barbatimão [Stryphnodendron adstringens (Mart.) Coville no
Distrito Federal, Brasil. Revista Árvore, Viçosa, v. 27, n. 5, p. 735-745, 2003.

BREDEMEIER, C.; MUNDSTOCK, C. M. Regulação da absorção e assimilação do nitrogênio nas plantas. Ciência Rural, Santa Maria, v. 30, n. 2, p. 365-372, 2000.

BRONDANI, G. E. et al. Phosphorus nutrition in the growth of Bauhinia forficata L. seedlings. Acta Scientiarum Agronomy, Maringá, v. 30 supl, p. 665-671, 2008.

BROUGHTON, W. J. et al. Signals exchanged between legumes and Rhizobium: agricultural uses and perspectives. Plant and Soil, Dordrecht, v. 252, n. 1, p. 129-137, 2003.

CALGARO, H. F. et al. Adubação química e orgânica na recuperação da fertilidade de subsolo degradado e na micorrização do Stryphnodendron polyphyllum. Revista Brasileira de Ciência do Solo, Viçosa, v. 32, n. 3, p. 1337-1347. 2008.

CARLOS, L. Requerimentos nutricionais de mudas de favela, pequi, marolo e barbatimão. 2009. 57 f. Dissertação (Mestrado) - Universidade Federal de Lavras, Lavras-MG, 2009.

Claessen, M. E. C. (Org.). Manual de métodos de análises de solo. 2. ed. Rio de Janeiro: EMBRAPA-CNPS, 1997. 212 p.

CRUZ, J. L. et al. Efeito do nitrato e amônio sobre o crescimento e eficiência de utilização do nitrogênio em mandioca. Bragantia, Campinas, v. 65 , n. 3 , p. 467-475, 2006.

EBERHARDT, D. N. et al. Influência da granulometria e da mineralogia sobre a retenção do fósforo em latossolos sob pastagens no cerrado. 
Revista Brasileira de Ciência do Solo, Viçosa, v. 32, n. 3, p. 1009-1016, 2008.

EMBRAPA. Guia clima. Disponível em: $<$ http:// www.cpao.embrapa.br/clima/?1c=site/banco-dados/ construtor-basico >. Acesso em: 18 nov. 2010.

EPSTEIN, E.; BLOOM, A. J. Nutrição mineral de plantas: princípios e perspectivas. Londrina: Planta, 2006. 402 p.

FAGERIA, N. K. et al. Response of rice cultivars to phosphorus supply on a oxisol. Fertilizer research, Dordrecht, v. 16, n. 3, p. 195-206, 1988.

FERNANDES, L. A. et al. Níveis de nitrogênio, fósforo e potássio para a produção de mudas de fava d'anta (Dimorphandra mollis Benth). Revista Brasileira de Plantas Medicinais, Botucatu, v. 10, n. 1, p. 94-99, 2008.

FONSECA, M. B. et al. Crescimento inicial de Dimorphandra wilsonii (Fabaceae Caesalpinioideae) em diferentes condições de fertilidade em solo de Cerrado. Acta Botânica Brasílica, São Paulo, v. 24, n. 2, p. 322-327, 2010. GODDARD R. E.; HOLLIS C. A. The genetic basics of forest tree nutrition. In: BOWEN G. D.; NAMBIER E. K.S. (Ed.) Nutrition of plantation forest. London: Academic Press, 1984. 516 p. GONÇALVES, E. O. et al. Nutrição de mudas de angico-vermelho (Anadenanthera macrocarpa (BENTH.) BRENAN) submetidas a doses de N, P, $\mathrm{K}, \mathrm{Ca}$ e Mg. Revista Árvore, Viçosa, v. 36, n. 2, p. 219-228, 2012.

HARIDASAN, M. Nutritional adaptations of native plants of the Cerrado biome in acid soils. Brazilian Journal of Plant Physiology, Campos dos Goytacazes, v. 20, n. 3, p. 183-195, 2008.

HEPLER, P. K. Calcium: a central regulator of plant growth and development. Plant Cell, Danvers, v. 17, n. 8 , p. $2142-2155,2005$.

LOPES, G. C. et al. Determinação quantitativa de taninos em três espécies de Stryphnodendron por cromatografia líquida de alta eficiência. Brazilian Journal of Pharmaceutical Sciences, São Paulo, v. 45, n. 1, p. 135-143, 2009.

LORENZI, H. Árvores brasileiras. 4. ed. Nova Odessa: Instituto Plantarum, 2002. v. 2, 202 p.

MALAVOLTA, E. et al. Avaliação do estado nutricional das plantas: princípios e aplicações. Piracicaba: POTAFOS, 1997. 319 p.

MARQUES, V. B. et al. Efeito de fontes e doses de nitrogênio sobre o crescimento Inicial e qualidade de mudas de jacarandá-da-bahia (Dalbergia nigra (Vell.) Fr. All. ex Benth.). Revista Árvore, Viçosa, v. 30, n. 5 , p. $725-735,2006$.
MARSCHNER, H. Mineral nutrition of higher plants. 2. ed. San Diego: Academic, 1995. 889 p. MARTINOIA, E.; MASSONNEAU, A.; FRANGNE, N. Transport processes of solutes across the vacuolar membrane of higher plants. Plant and Cell Physiology, Kyoto, v. 41, n. 11, p. 1175-1186, 2000.

NEVES, O. S. C. et al. Crescimento, produção de massa seca e acúmulo de $\mathrm{N}, \mathrm{P}, \mathrm{K}, \mathrm{Ca}, \mathrm{Mg}$ e $\mathrm{S}$ na parte aérea de mudas de andiroba (Carapa guianensis Aubl.) cultivadas em solo de várzea, em função de diferentes doses de fósforo. Revista Árvore, Viçosa, v. 28, n. 3, p. 343-349, 2004.

NICOLOSO, F. T. et al. Exigências nutricionais da grápia em Argissolo Vermelho distrófico arênico: (II) Efeito da adubação NPK no teor de nutrientes nos tecidos. Ciência Rural, Santa Maria, v. 37, n. 2, p. 372-380, 2007.

PAULA, R. C. et al. Controle genético da eficiência de utilização de fósforo em famílias de meios-irmãos de Eucalyptus grandis, em casa de vegetação. Revista Árvore, Viçosa, v. 27, n. 1, p. 15-23, 2003.

PROCÓPIO, S. O. et al. Absorção e utilização do nitrogênio pelas culturas da soja e do feijão e por plantas daninhas. Planta Daninha, Viçosa, v. 22, n. 3, p. 365-374, 2004.

RESCK, D. V. S. et al. Dinâmica da matéria orgânica no Cerrado. In: SANTOS, G. A. et al. (Eds.). Fundamentos da matéria orgânica do solo: Ecossistemas tropicais \& Subtropicais. 2. ed. Porto Alegre: Metrópole, 2008. 645 p.

RIBEIRO JÚNIOR, J. I.; MELO, A. L. P. Guia prático para utilização do SAEG. Viçosa: UFV, 2009. $287 \mathrm{p}$.

RODRIGUES, V. E. G.; CARVALHO, D. A. Plantas medicinais no domicílio do Cerrado. Lavras: UFLA, 2001. 236 p.

ROSOLEM, C. A.; FOLONI, J. S. S.; OLIVEIRA R. H. Dinâmica do nitrogênio no solo em razão da calagem e adubação nitrogenada, com palha na superfície. Pesquisa Agropecuária Brasileira, Brasília, v. 38, n. 2, p. 301-309, fev. 2003.

SANTOS, R. A. et al. Adubação fosfatada para a produção de mudas de mogno (Swietenia macrophylla King). Acta Amazônica, Manaus, v. 38, n. 3, p. 453-458, 2008.

SCABORA, M. H. et al. Associação micorízica em espécies arbóreas, atividade microbiana e fertilidade do solo em áreas degradadas de Cerrado. Ciência Florestal, Santa Maria, v. 21, n. 2, p. 289-301, 2011. SCHOLZ, F. G. et al. Removal of nutrient limitations 
by long-term fertilization decreases nocturnal water loss in savanna trees. Tree Physiology, Victoria, v. 27, p. 551-559, 2006.

SIDDIQI, M.; GLASS, A. D. M. Utilization index: a modified approach to the estimation and comparison of nutrient utilization efficiency in plants. Journal of Plant Nutrition, New York, v. 4, p. 289-302, 1981.

SILVA, R. F. et al. Comportamento de Peltophorum dubium (Spreng.) Taub., Parapiptadenia rigida (Benth.) Brenan e Enterolobium contortisiliquum (Vell.) Morong cultivadas em solo contaminado com cobre. Ciência Florestal, Santa Maria, v. 21, n. 1, p. 103-110, 2011.

SOUZA, C. A. S. et al. Exigências nutricionais e crescimento de plantas de mogno (Swietenia macrophylla King.). Acta Amazônica, Manaus, v. 40, n. 3, p. 515-522, 2010.

SOUZA, P. A. et al. Adubação mineral do ipê-roxo (Tabebuia impetiginosa). Ciência Florestal, Santa Maria, v. 16, n. 3, p. 261-270, 2006.

SWIADER, J. M. et al. Genotypic differences in nitrate uptake and utilization efficiency in pumpkin hybrids. Journal of Plant Nutrition, New York, v. 17, p. 1687-1699, 1994.

TAIZ, L.; ZEIGER, E. Fisiologia vegetal. 5. ed. Porto Alegre: Artmed, 2013. 954 p.

TOMAZ, M. A. et al. Eficiência de absorção, translocação e uso de cálcio, magnésio e enxofre por mudas enxertadas de Coffea arábica. Revista Brasileira de Ciência do Solo, Viçosa, v. 27, n. 5, p. 885-892, 2003.

VENTURIN, N. et al. Adubação mineral do angicoamarelo (Peltophorum dubium (Spreng.) Taub.). Pesquisa Agropecuária Brasileira, Brasília, v. 34, n. 3, p. 441-448, 1999.

VIEIRA, M. C. et al. Nitrogênio e fósforo no desenvolvimento inicial da guavira [Campomanesia adamantium (Cambess.) O. Berg cultivada em vasos. Revista Brasileira de Plantas Medicinais, Botucatu, v. 13, nesp, p. 542-549, 2011.

VITTI, G. C.; LIMA, E.; CICARONE, F. Cálcio, magnésio e enxofre. In: MANLIO, S. F. (Ed.). Nutrição mineral de plantas. Viçosa: Sociedade Brasileira de Ciência do Solo, 2006. p. 299-325.

VON WIRÉN, N. et al. Regulation of mineral nitrogen uptake in plants. Plant and Soil, Den Haag, v. 196, p. 191-199, 1997. 